\title{
Successful endoscopic removal of fractured guidewire fragments from a peripheral bile duct using a biliary stent delivery system and biopsy forceps
}

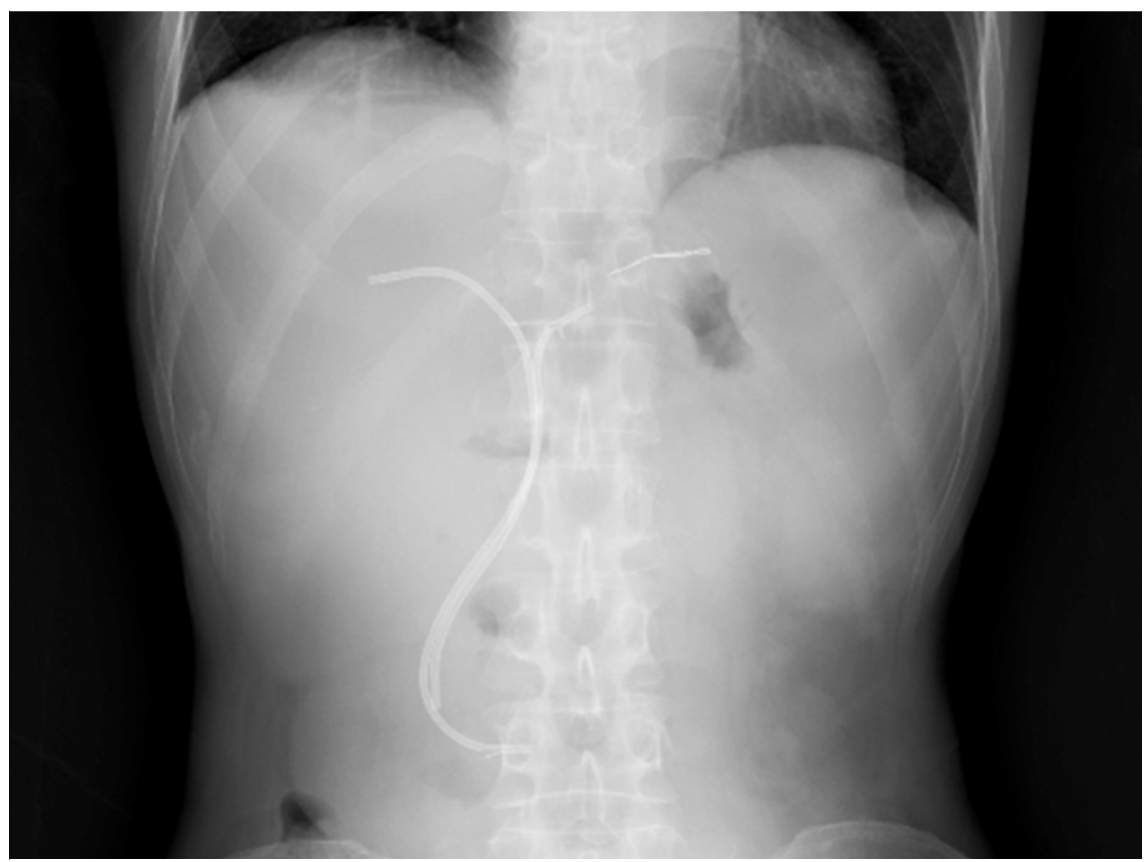

- Fig. 1 Abdominal radiograph showing two plastic biliary stents and a foreign body.

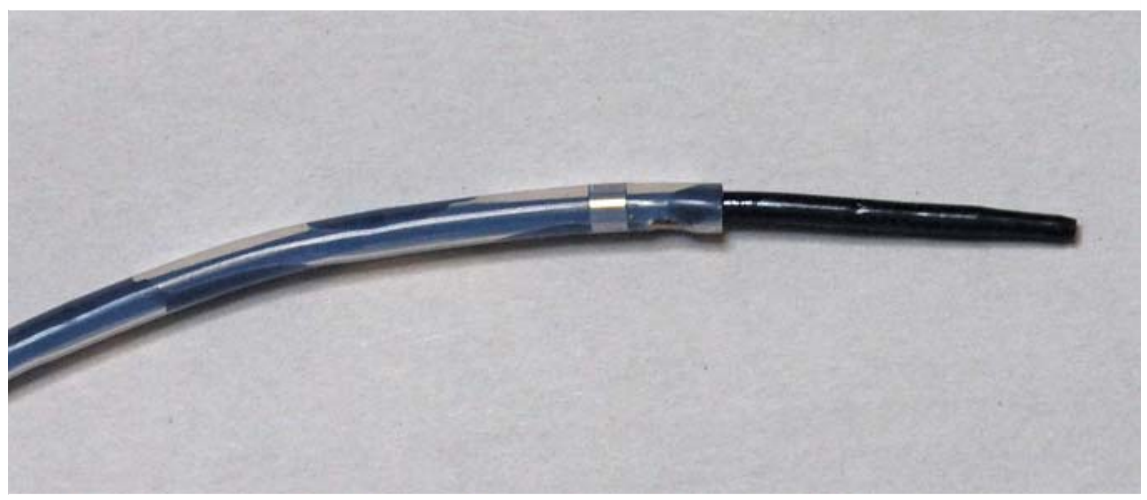

- Fig. 3 Photograph of the introducer tube and pusher tube of the biliary stent delivery system used in this technique. Both devices have radiopaque markers on the tip.

A 61-year-old man with sclerosing cholangitis was referred to our hospital. Blood tests on admission suggested he had acute cholangitis. An abdominal radiograph revealed, in addition to two plastic biliary stents, a foreign body in the upper abdominal area, which appeared to be a fractured guidewire fragment in a peripheral bile duct that had remained after endoscopic retrograde cholangiopancreatography (ERCP) performed at the previous hospital ( $\$$ Fig. 1).

A further ERCP was performed in our facility for acute cholangitis and removal of the fragments. Cholangiography revealed a biliary stricture from the hilar to peripheral bile ducts, in which guidewire fragments were identified (

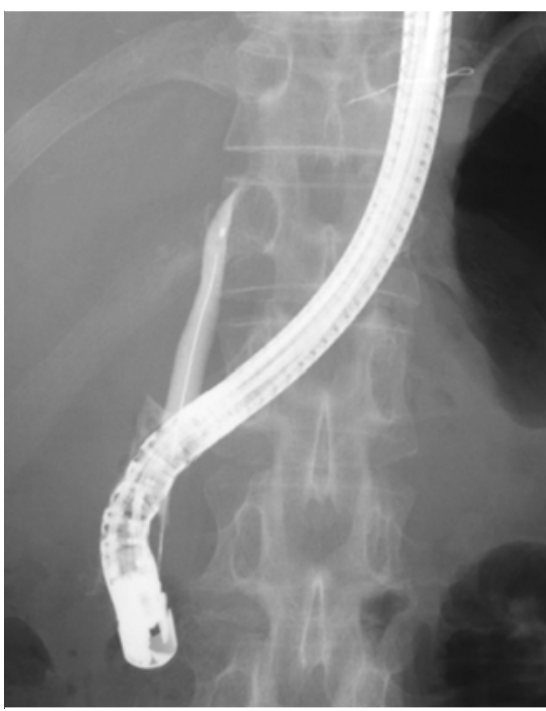

- Fig. 2 Cholangiographic image showing a biliary stricture from the hilar to peripheral bile ducts, in which the fractured guidewire fragments were seen.

After the duct had been dilated with a 7-Fr dilator (Soehendra dilation catheter; Cook Japan, Japan), the introducer tube and pusher tube of a biliary stent delivery system (Gadelius Medical, Japan) ( $\triangleright$ Fig.3) were inserted. Once the tip of the pusher tube reached the fragments, the introducer tube was withdrawn and the guidewire fragments were removed through the pusher tube with biopsy forceps (Radial Jaw 4 Pediatric Biopsy Forceps; Boston Scientific Japan, Japan) ( $\triangleright$ Fig. 4 and $>$ Fig. 5; Video 1). Finally, endoscopic nasobiliary drainage tubes were placed in the bilateral hepatic ducts. The patient's acute cholangitis improved following this procedure.

Although there are several reports of fractured guidewires being present in the bile ducts, removal of guidewire fragments from a peripheral bile duct has not previously been reported [1-4]. To remove the fragments, we modified the previously reported method for a "mapping biopsy" of the bile duct using a Soehendra dilation catheter and biopsy 


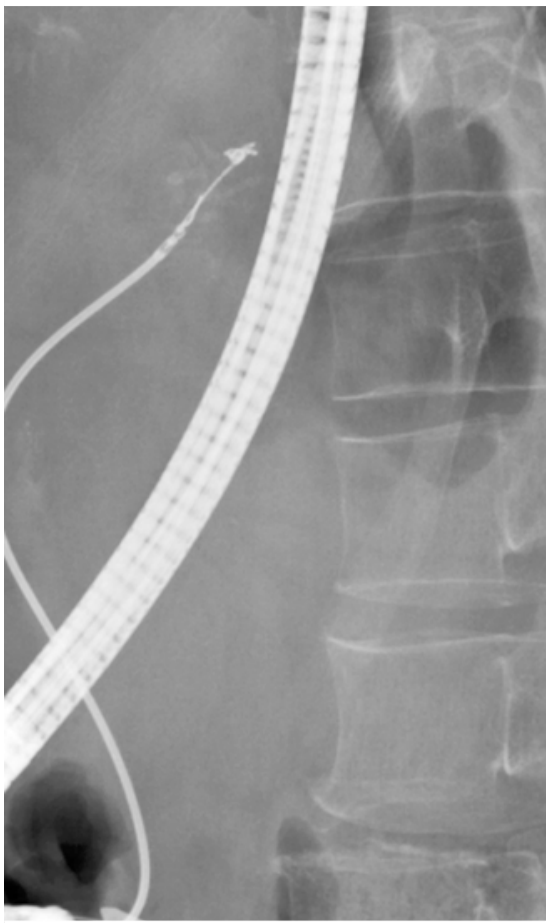

> Fig. 4 Radiographic image showing forceps inserted to remove the guidewire fragments through the pusher tube.

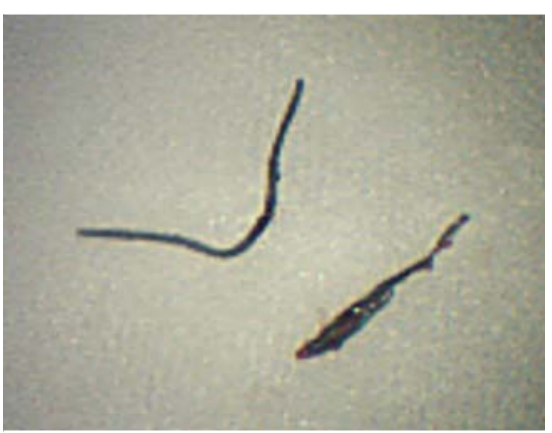

Fig. 5 The removed guidewire fragments.

forceps [5]. This technique can deliver various devices to the target site easily and accurately. In addition, it may decrease the risk of acute pancreatitis by reducing the burden on the duodenal papilla that is caused by the frequent insertion and removal of devices.

In conclusion, we report a novel technique to retrieve a foreign body, such as a fractured guidewire fragment, from a peripheral bile duct.

Endoscopy_UCTN_Code_TTT_1AR_2AG
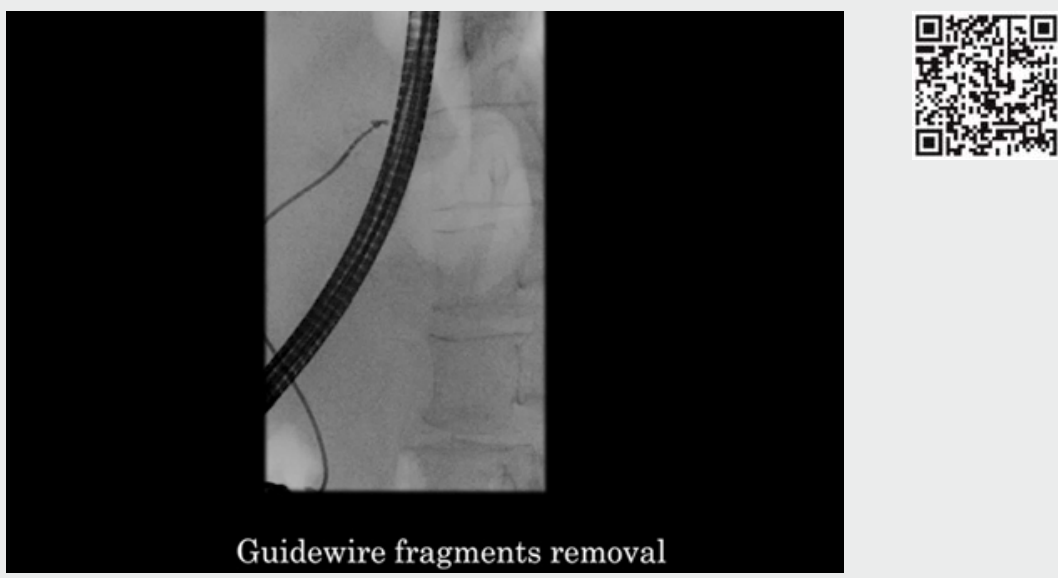

Video 1 The procedure for removal of the guidewire fragments using the introducer and pusher tube of a biliary stent delivery system and biopsy forceps.

\section{Competing interests}

None

The authors

Yoshihiro Nishikawa, Norimitsu Uza, Yuki Yamauchi, Akihisa Fukuda, Yoshihide Ueda, Yuzo Kodama, Hiroshi Seno Department of Gastroenterology and Hepatology, Graduate School of Medicine, Kyoto University, Kyoto, Japan

\section{Corresponding author}

\section{Norimitsu Uza, MD}

Department of Gastroenterology and Hepatology, Kyoto University Graduate School of Medicine, 54 Kawara-cho, Shogoin, Sakyo-ku, Kyoto, Japan

Fax: +81-75-7514302

uzanori@kuhp.kyoto-u.ac.jp

\section{References}

[1] Burdick JS, Schmalz M], Geenen JE. Guidewire fracture during endoscopic sphincterotomy. Endoscopy 1993; 25: 251-252

[2] Heinerman M, Mann R, Boeckl O. An unusual complication in attempted non-surgical treatment of pancreatic bile duct stones. Endoscopy 1993; 25: $248-250$

[3] Fry LC, Linder JD, Monkemuller KE. Cholangitis as a result of hydrophilic guidewire fracture. Gastrointest Endosc 2002; 56 : $943-944$
[4] Pomeranz CB, Wehrli NE, Tyberg A et al. Unusual migration of fractured ERCP guidewire: A case report. Clin Imaging 2017; 43: 93-96

[5] Hijioka S, Hara K, Mizuno N et al. A novel technique for endoscopic transpapillary "mapping biopsy specimens" of superficial intraductal spread of bile duct carcinoma (with videos). Gastrointest Endosc 2014; 79 : $1020-1025$

Bibliography

DOI https://doi.org/10.1055/a-0641-4989

Published online: 3.7.2018

Endoscopy 2018; 50: E279-E280

(c) Georg Thieme Verlag KG

Stuttgart · New York

ISSN 0013-726X

\section{ENDOSCOPY E-VIDEOS}

https://eref.thieme.de/e-videos

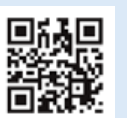

Endoscopy E-Videos is a free access online section, reporting on interesting cases and new techniques in gastroenterological endoscopy. All papers include a high quality video and all contributions are freely accessible online.

This section has its own submission website at

https://mc.manuscriptcentral.com/e-videos 